\title{
Suprarenal Artery
}

National Cancer Institute

\section{Source}

National Cancer Institute. Suprarenal Artery. NCI Thesaurus. Code C33708.

An artery located in the abdomen that provides blood to the adrenal glands. 